\title{
Málaga y Melilla durante la transición de los Austrias a los Borbones
}

$M^{a}$ Isabel Pérez de Colosía Rodríguez

Investigadora responsable del grupo: "Equipo interdisciplinar Málaga Moderna". Coordinadora del Area de Historia Moderna, Lniversidad de Málaga, 1991

Una de las etapas más tensas de la. Historia de España fue la transición de la Casa de Austria a la Borbónica, pues el cambio dinástico provocó una guerra que, desbordando el escenario nacional, saltó al internacional.

En este trabajo vamos a analizar algunos aspectos de la situación militar de Málaga antes y durante el conflicto bélico, así como sus relaciones con Melilla, basándonos, respecto al tema malagueño, en las fuentes seriadas que forman los Libros de Actas del cabildo municipal y en la Colección de Originales, custodiadas en el Archivo Municipal de Málaga.

La conflictividad de las aguas del Mediterráneo Occidental hizo que, durante toda la Edad Moderna, ambas plazas estuviesen en constante estado de alerta. En primer lugar, han de señalarse las continuas correrías llevadas a cabo por la piratería turca y berberisca que asolaban las tierras malagueñas; problema de manifiesto carácter secular, pues aunque su época de apogeo se corresponde con el siglo XVI, seguiría representando un serio peligro durante las dos centurias siguientes.

Si Cisneros comenzó en las costas de Africa una guerra de Cruzada, Carlos I y Felipe II, tuvieron siempre presente en su política la instalación de un cordón de presidios donde apoyarse para controlar la zona del Estrecho, además de mantener una cabeza de puente para ampliar sus domi- 
nios en el continente africano (1). Política que sería refrendada por los últimos Austrias y el primer Borbón, pero a partir de este último reinado, los monarcas borbónicos comenzaron a cuestionarse la eficacia de los presidios norteafricanos, dado que su existencia ni acabó con las incursiones piráticas a la costa del Reino de Granada, ni con las llevadas a cabo por las armadas francesas, inglesas u holandesas, según la política beligerante del momento.

En defensa de su litoral, el municipio malagueño se vio obligado a reparar o aumentar las torres almenaras que jalonaban la costa (2). Con ellas pretendía evitar, principalmente, los asaltos de los musulmanes de allende el mar, cuya finalidad era apresar cautivos cristianos que llevaban al norte de Africa para, desde allí, exigir sumas de dinero a cambio del rescate. Las cantidades demandadas venían a ser más o menos cuantiosas según la calidad de la persona apresada, pero siempre resultaban un pingüe negocio. Negocio al que se contraponía la captura de islámicos, llevada a cabo por los cristianos, con el objeto de venderlos como esclavos en el floreciente mercado esclavista malacitano; sin dejar nunca de lado la lucrativa práctica del corso, que se mantendrá hasta el siglo XVIII (3).

Desde las torres almenaras, los vigías alertaban a la ciudad de la llegada de barcos piratas o de las armadas enemigas, para que en la ciudad, villas y lugares se llamase a rebato, con objeto de preparar su defensa ante el inminente peligro. A esta llamada de alarma acudían prestas las milicias concejiles, urbanas o rurales, a fin de rechazar el repentino asalto.

Sin embargo, es en tales casos cuando se demuestra, con demasiada frecuencia, la inoperancia de dichas milicias, siendo uno de los motivos básicos de su ineficacia la falta de los pertrechos suficientes, como comprobamos en el memorial que, en 1673, eleva el alcalde de Benalmádena al corregidor, mediante el cual solicitaba:

Se le asista con la cantidad de pólvora que a esta çiudad paresiere para los vecinos de aquella villa, respecto de averse hallado esta semana con los moros que an saltado en tierra en la plaia de aquella villa y la de Mixas, y no tenía con qué haçerles agravio, ni tener dichos vecinos caudal para comprar dicha pólvora (4).

El texto pone de manifiesto la inseguridad de la costa andalu- 
za durante el reinado del último Austria, circunstancia que conllevaba la necesidad de mantener una fuerte relación militar entre Málaga y los presidios norteafricanos, fundamentalmente con Melilla. Así, tenemos que desde el puerto malagueño salían los barcos hacia este presidio con los bastimentos y hombres necesarios, para que estuviese siempre bien guarnecida. Las embarcaciones dedicadas a este transporte no solían ser de gran envergadura, utilizándose preferentemente saetías, tartanas, jabeques, etc., cuyo tonelaje oscilaba entre los 100 y los 500 quintales (5).

En las remesas de víveres expedidas, abundaba el aceite, vino, vinagre, pasa, cebada, trigo, harina, sal, legumbres...; además de las provisiones basadas en el salazón, de carne o pescado, y el bizcocho, surgiendo una industria alimenticia muy digna de tener en cuenta, en gran parte destinada a abastecer los presidios. No podemos olvidar nunca un envío fundamental: los pertrechos militares, destacando entre ellos las armas, pólvora, municiones, caballos, ropa militar, etc.; a todo lo cual había que añadir la cal, los ladrillos y, en general, los materiales necesarios para la construcción de las fortificaciones. Mención aparte merece el zumaque, curtiente muy utilizado en la época.

Por supuesto, el envío de hombres a fin de mantener la guarnición necesaria, sobre todo en los momentos de máximo peligro, resultaba el tema más conflictivo, pues, a pesar de las exenciones ofertadas por Carlos II y Felipe V, casi no existían soldados voluntarios dispuestos a marchar a las plazas norteafricanas, hecho que, en ocasiones, hizo necesario mandar presidiarios o vagabundos. Referente a este último caso tenemos una relación, fechada en 1690 , donde se registran 74 malhentretenidos, de los cuales el $47 \%$ estaba destinado a Melilla (6).

En el siglo XVII, la mayor amenaza proveniente de las aguas del Mediterráneo Occidental consistía en los ataques de las poderosas escuadras, enviadas por los gobiernos de aquellos países europeos con los que la Corona española estuviese en guerra.

Cuando los escuchas de las torres vigías avistaban una de estas armadas, el corregidor de Málaga convocaba urgentemente a cabildo. La primera medida a tomar, consistía en el nombramiento de una Junta de Guerra formada por varios regidores diputados que, en unión de los mandos militares, organizaba la defensa de la ciudad y sus tierras. Inmediatamente se pasaba a inspeccionar las fortificaciones y a revisar el armamento 
existente, obteniendo siempre resultados bastante negativos. Al igual que en reconocimientos anteriores, los castillos, baluartes y murallas seguían manteniendo unas condiciones muy deficientes, siendo imprescindible repararlos y, además, construir otros nuevos bastiones. El panorama no era más optimista respecto al armamento: escasez de municiones, piezas de artillería en malas condiciones o de corto alcance, cureñas podridas o inexistentes etc., solían estar al orden del día. Había que subsanar las carencias existentes, pero la falta de medios económicos coartaba cualquier empresa que deseara realizar la Junta de Guerra, comenzando un tira y afloja entre el municipio y el poder central para buscar el medio de financiación con el que estuviesen de acuerdo ambas partes.

En las cuestiones castrenses, el factor humano tampoco desempeñaba un papel muy afortunado. Las fuerzas que soportaban el peso de la defensa de la ciudad y de sus tierras eran las milicias concejiles, tanto las de la capital como las de las villas y lugares de su jurisdicción, acudiendo también en los casos de alto riesgo las de Antequera, Ronda y Vélez-Málaga. Pero, como apuntamos anteriormente, en ellas subyacían notables deficiencias, por lo cual resultaban inoperantes ante los asaltos de las grandes escuadras enemigas.

Lo más notorio de la época que estamos estudiando es, sin duda, la actuación de dichas milicias cuando, en 1693, es atacada Málaga por la armada francesa, comandada por el mariscal Tourville. En tal ocasión, se puso en evidencia la falta de disciplina, entrenamiento y armas que tenían las milicias urbanas y rurales, sobre todo estas últimas, que llegaron a defender la ciudad sin tan siquiera portar armas y municiones (7).

Desde que Carlos II rompiese las hostilidades con Luis XIV, Málaga se vio envuelta en una serie de episodios, un tanto comprometidos, ante la presencia de las armadas francesas en aguas del Mediterráneo Occidental, incursiones que se hacen más numerosas en la última década del reinado del monarca hispano. Uno de los momentos de más peligro fue cuando, en 1692, una escuadra gala arribó a la bahía malagueña y, si bien no bombardeó la ciudad como lo haría al año siguiente, sí obstaculizó su comercio, puesto que los barcos que recorrían los circuitos mercantiles mediterráneos temían pasar por la zona y, más aún, al tener noticia de que los franceses capturaron o quemaron diez navíos ingleses anclados en la bahía, los cuales habían arribado a ella para cargar productos malagueños, 
y en los que "los vecinos fiaban la salida de frutos, aunque fuese a cortos precios", dada la imposibilidad de venderlos a otras flotas mercantes (8). La diplomacia del gobernador malacitano logró, mediante embajadas y regalos, que los galos se retirasen sin ocasionar más daños que los puramente económicos.

Puesta de manifiesto la indefensión de Málaga, la Corona mandó al municipio que dotara a la ciudad de todo lo necesario para poder rechazar con éxito los posibles ataques, y evitar nuevos desastres como el acaecido en 1693. El panorama internacional no era muy halagüeño para España y se temían nuevas confrontaciones bélicas, dado que los diplomáticos europeos estaban intrigando de forma notoria, buscando un sucesor a Carlos II que fuese natural de sus respectivos países, o beneficiase sus intereses. La transición se presentaba difícil y problemática, por tanto estaba latente el temor de una gran guerra, como así acaecería.

Una de las medidas adoptadas por el monarca y su Consejo de Guerra fue el que se hiciesen planos del sistema defensivo de la ciudad, para así analizar el estado del mismo, redactándose con los resultados los informes correspondientes, donde quedaban explicitadas las reparaciones más precisas y sus costos.

Hércules Toreli - arquitecto, ingeniero, matemático y capitán de caballería - fue el encargado de realizar una minuciosa inspección de los castillos, fuertes, baluartes $y_{2}$ sobre todo, del recinto amurallado. De resultas, en 1693, levantó una planta de la ciudad donde recogió de forma minuciosa la infraestructura defensiva de Málaga (9). Toreli, analizó sobre el terreno las deficiencias en las construcciones militares, y dictaminó cuáles habían de construirse, o repararse, para garantizar la defensa de la capital ante los ataques que se esperaban fuesen sucediéndose, debido al citado problema sucesorio de la Corona española.

Junto al plano de la ciudad, Hércules Toreli remitió un informe al monarca y a su Consejo de Guerra, donde comenta, entre otros temas, lo siguiente:

El cuerpo de la plaza es corrido de una muralla antigua de figura y regular, tiene en él diez puertas principales sin ninguna defensa, y la mayor parte del recinto está parte derrotado y parte caído que necesita de repararlo, $y$ 
esta plaza no es capaz de fortificarla respecto de estar ceñida con los arrabales, como se ve en la planta (10).

Otra cuestión que se plantea el ingeniero es el problema de las inundaciones causadas por los desbordamientos del río Guadalmedina, buscando una solución donde lo militar tuviese también cabida. De acuerdo con tal opción, decide "hacer un recinto de muralla a dientes" que recorriese la margen izquierda del río, la cual serviría de muro de contención de las aguas fluviales cuando hubiese avenida y, al mismo tiempo, salvaguardaría la zona oeste de Málaga. El valor defensivo del murallón quedaría reforzado en la parte de mayor peligro, la marítima, gracias a una "plataforma que serviría de batería", desde donde podría rechazarse, con eficacia, cualquier desembarco enemigo en la playa de poniente. Esta zona costera, había quedado indefensa desde que el bastión de Torre Gorda perdió su valor estratégico con la retirada del mar y el consiguiente aumento de las arenas del litoral, por lo tanto, el alcance de tiro de su artillería no podía llegar a las embarcaciones enemigas que arribasen a la costa malagueña por poniente (11). Por otra parte, el estado ruinoso de las fortalezas se había visto agravado con los destrozos causados por el terremoto de 1680 , siendo de una necesidad inminente su reparación.

Todas estas circunstancias, motivaron que el concejo solicitase al monarca autorización para poder costear la rehabilitación del sistema defensivo con los arbitrios y arrendamientos municipales, los cuales ascendían a unos 6.000 o 7.000 ducados, a pesar de que tal medida supusiera el aumento del secular déficit del ayuntamiento (12).

Respecto al recinto murado que miraba al mar, Toreli optó por construir un parapeto que fuese desde el Torreón del Obispo hasta Puerta Oscura, el cual serviría también de vía de comunicación que recorrería la playa de levante, evitando a los viandantes el dar una serie de rodeos y, a la vez, beneficiaría el comercio, ya que facilitaría la entrada de los arrieros, trajineros, porteadores y, sobre todo, de los mercaderes que venían desde Vélez-Málaga con diversos productos destinados al mercado malacitano (13).

En su informe, el ingeniero incluye un estudio económico en el que evalúa los costes y el tiempo necesario para llevar a cabo el proyecto: En cuanto al gasto destas obras y reparos monta- 
rá, según el tanteo, cien mil ducados, y el tiempo que se podrá emplear en ella serán dos años, algo más o menos, y no se puede dar tiempo cierto respecto que la mayor parte de esta obra está sujeta a las abenidas de las aguas, $y$ otros acidentes que pueden ocurrir en tales fábricas, $y$ haberse de hacer en toda de ormigón, ques cal, arena y cascajo (14).

La economía del concejo malagueño y de la Real Hacienda no se encontraba en condiciones de sufragar tales gastos, motivo por el que las obras no se llevarían a cabo, a pesar de emplearse para tal fin, en 1695, los arbitrios destinados "a la fábrica de las cañerías del agua" y el producto de los oficios cadañeros, ordenando, un año más tarde, que comenzaran las obras en las fortalezas y se las artillara con nuevas piezas (15).

Sin embargo, hasta el advenimiento al trono de Felipe $\mathrm{V}$ no se iniciaría la construcción del fuerte de San Lorenzo que venía a estar ubicado, aproximadamente, donde Toreli situó la plataforma abaluartada que remataría la muralla de dientes de sierra, delineada en la ribera del Guadalmedina (16). Tampoco se llevaron a cabo las reformas del sistema defensivo dictaminadas a finales de la centuria anterior, motivo por el cual, en 1702, el Borbón mandó ponerlas de nuevo en vigencia, prorrogándose también el uso de los arbitrios, según ya lo había autorizado el último de los Austrias (17).

Aunque no hemos encontrado datos que nos lo confirme, parece ser que, en 1693, Toreli pasó a Melilla para comprobar el estado de las fortificaciones del presidio que tan ligado estaba a Málaga, como lo demuestra el hecho de que muchos de los ingenieros militares destinados a la capital malacitana para revisar su sistema defensivo, marchen a la ciudadela melillense con la misma finalidad, pues, apoyada en ambas plazas, España podía controlar mejor la zona marítima comprendida entre ellas.

La estratégica situación geopolítica de Melilla, había repercutido en que su devenir histórico atravesara por muy diversos avatares, desde su fundación por los fenicios hasta que fue conquistada por las huestes de Medina Sidonia (18). Castilla emplazaría en ella una ciudadela bien fortificada, en consonancia con la política de la Corona, deseosa de establecer una serie de presidios en posiciones avanzadas, cuyo fin consistía en ampliar sus dominios sobre el territorio norteafricano, pero teniendo siem- 
pre presente que dichas plazas mantuviesen una comunicación marítima, más o menos directa, con la metrópoli (19).

Desde que Melilla fue conquistada por los cristianos hasta finales de la Edad Moderna, la fortaleza no excede, prácticamente, del límite de sus murallas, que serán las que más transformaciones experimenten durante los siglos XVII y XVIII. Aunque la ciudadela mantenía relaciones comerciales con las tierras de su entorno, como veremos más tarde, éstas eran más bien de tipo de subsistencia, pues no ha de olvidarse que Melilla fue concebida como una plaza fuerte, cuyas principales funciones venían a ser las de vigía y defensa, tanto de las tierras norteafricanas como de las aguas del Mediterráneo (20). En consecuencia, todo lo que se construya en ella estará relacionado con su condición militar y, únicamente, aquello que fuere imprescindible, tendría un carácter civil, que no se destacaría por la calidad de sus materiales o arquitectura, a excepción de la dieciochesca Casa de los Lafont (21).

De acorde con todo lo expuesto, la estructura socio-profesional de sus vecinos girará en torno de la naturaleza castrense de Melilla (22). Así, el cuerpo militar que conformaba el destacamento del presidio lo componía, en el siglo XVII, un alcaide, oficiales de las distintas fuerzas de a pie o a caballo, jinetes, artilleros, ballesteros, piqueros... que alcanzaban el porcentaje más elevado de la población (23). Junto a ellos, se hallaba el personal para los servicios civiles y religiosos, entre los que podemos citar el sacerdote, el sacristán, diversos artesanos, canteros, esclavos... además de las mujeres y niños (24). Mención aparte, merece el establecimiento judío, cuya presencia en la fortaleza se detecta desde principios del siglo XVI, según demuestra Salafranca Ortega (25).

En el aspecto económico, ya apuntado anteriormente, ha de reseñarse que el presidio había estado firmando, desde el siglo XVI, una serie de tratados o alafias de tipo comercial con las cábilas de su entorno, siendo la última de la que se tienen noticias la de 1606. Durante dichas treguas, "los rifeños pagaban una cantidad de trigo, cebada, miel o cera, a proporción de un caíz de simiente por yunta, para labrar y sembrar en la vega de Melilla", que estaba defendida por los fuertes exteriores. Pero tales relaciones, se irán enturbiando posteriormente, llevándose a cabo una serie de razzias mediante las cuales se capturaban a los habitantes de las cábilas para venderlos como esclavos, se liberaban los cautivos cristianos, y se 
requisaba la ganadería de la zona (26).

Las obras llevadas a cabo en el Seiscientos, además de casas y cuarteles, siguen siendo de reparación o construcción de nuevos elementos de fortificación, formándose una línea de vanguardia, cuya finalidad era avanzar en un proceso de apropiación del territorio, que va configurando el urbanismo de la ciudadela, la cual, en esta centuria, va a iniciar un transcendental cambio, pues adquiriría la categoría de ciudad gracias a que Felipe III le otorgó, en 1613, el privilegio de dicho título. Entre las obras efectuadas, tenemos la reconstrucción del túnel de Santa Ana, el fuerte de San Pedro de la Albarrada, Santo Tomás de la Cantera; al tiempo que se reparaban los fuertes de Santiago, San Marcos, San Lorenzo y las murallas de la Alafia o Villa Vieja y la muralla Real (27).

El terremoto acaecido el 24 de septiembre de 1660 , destruyó gran parte de los edificios y sistema defensivo, por lo cual fue necesario volver a rehabilitarlos. La Corona, ante tal desastre, envió 4.000 ducados para costear la reparación de fuertes, torreones y murallas. Sin embargo, en esta ocasión no se siguieron las técnicas más avanzadas del momento, ya que las reconstrucciones corrieron a cargo de maestros de obras y de personal no cualificado, sin contar con la dirección de ingenieros militares. El seísmo conllevó otra faceta, como fue la incidencia negativa en el crecimiento demográfico melillense que posteriormente decaería, de forma espectacular a causa de los estragos ocasionados por la peste de 1680 , en la cual murieron centenares de personas (28).

Durante el reinado de Carlos II se evidencia un mayor interés del poder central acerca de la plaza fuerte de Melilla, buscándose un nuevo sistema de defensa que Argente del Castillo resume de la siguiente forma:

El tipo de fortificación cambia; aunque con retraso, aparecen ahora en Melilla una serie de innovaciones técnicas de origen holandés que cambian los esquemas de la fortaleza, y por tanto el espacio construido; el recinto de la Alafia, a descubierto de la altura del Cubo, queda reforzado en su línea, frente al campo moro, con un esquema de fortificación compuesto por un hornabeque formado por dos baluartes $y$ una cortina que los une, delante del cual se sitúa una media luna. Los baluartes son dos torres de tipo pentagonal, sufi- 
cientemente amplias para permitir el movimiento y disposición de las piezas de artillería en su interior; la cortina es la muralla recta que une los baluartes y la media luna servía para defender la puerta de entrada. Complementario de este esquema, en torno la Alafia, aparecen dos fuertes San José Bajo y Santiago. Además del esquema anterior es construido ahora un varadero con su baluarte defensivo: San Antonio de la Marina (29).

Con el último de los Austrias son destinados varios ingenieros militares para inspeccionar el sistema defensivo de la ciudadela y elevar sus memoriales al monarca, con el propósito de que se llevasen a cabo las obras pertinentes. Si bien, es cierto que tales dictámenes, con demasiada frecuencia, se convertían en papel mojado, debido a la carencia de medios de la Real Hacienda para financiar las reparaciones o construcciones proyectadas.

A pesar del déficit presupuestario, algunos de los ingenieros militares obtendrán ciertos logros, como es el caso de Octavio Meni, quien consiguió limpiar los fosos, hacer puentes levadizos, reedificar el torreón de las Beatas, sanear los aljibes, etc. Siempre contando con el apoyo decidido del gobernador, Toscano Brito. Posteriormente, a partir de 1689, comenzarán a levantarse la torre de la Concepción, la Media Luna, un hornabeque, además de los fuertes de San Antonio de la Marina, San José Bajo y Santiago (30).

En 1700 fallecía Carlos II, quien había ordenado el comienzo de una serie de reformas, fundamentalmente económicas y militares. Su muerte afectó a Málaga y Melilla, ya que tras ella fueron paralizadas las obras de fortificación, las cuales no volverán a reiniciarse hasta el advenimiento de Felipe V. El cambio de dinastía se realizó de forma violenta, tal como se esperaba en los últimos años del siglo XVII, provocándose la larga y costosa Guerra de Sucesión.

La subida al trono de un Borbón repercutió de forma manifiesta en España, dado que la influencia francesa se dejó notar en el sistema de gobierno y en las reformas que el rey intentó realizar. No obstante, como es lógico, durante la contienda no se produjeron grandes cambios, por cuanto, los cuantiosos gastos que suponía el confrontamiento bélico, hacía impracticable que la mayoría de ellos pudieran llevarse a efecto (31). 
A pesar de todo, Málaga no perdería la ocasión de presentar a Felipe $\mathrm{V}$ las carencias que sufría la ciudad, alegando al mismo tiempo las prestaciones económicas y de hombres que la ciudad hacía al monarca recién instaurado. A manera de ejemplo, podemos citar la prórroga de una serie de impuestos que, por un periodo de diez años, el concejo solicitó a la Corona con el fin de destinar esos fondos para iniciar algunas obras, como la muralla dentada - ya proyectada por Toreli- y la continuación del muelle, éste último sumamente necesario para el ancoraje de las galeras reales y las armadas (32).

Esta solicitud venía a redundar en la petición hecha años antes, donde se daba a conocer que la falta de atención a las obras portuarias había repercutido en la pérdida de parte de ellas. Circunstancia que estaba agravada porque un banco de arena había entrado en el surgidero a causa de los temporales, subiendo los fondos, motivo por el cual no podían anclar en el recinto los barcos mercantes, con el consabido perjuicio comercial (33).

Podemos constatar que la construcción del puerto, comenzada en tiempos de Felipe II y que casi no avanza durante los Austrias, se ve de nuevo ralentizada con la Guerra de Sucesión y no será reactivada hasta finalizar la contienda (34). Si bien, Málaga mantuvo un destacado protagonismo durante el conflicto, debido tanto a su carácter militar como a su proximidad al Estrecho de Gibraltar. Asimismo, se tenía muy en cuenta su función de "almacén" de las plazas norteafricanas, porque desde su puerto se las seguía proveyendo, al igual que en siglos anteriores, de hombres, pertrechos, caballos, materiales de construcción, víveres, etc.

Por todos los factores precitados, el gobierno central tuvo muy presente que Málaga sería uno de los objetivos puestos en el punto de mira de las escuadras anglo-holandesas. De hecho, hubo numerosas alarmas en los primeros años del siglo XVIII, de entre las cuales hemos sacado el siguiente muestreo:

En 1701, el capitán general de Andalucía dispone que el tercio de Segovia fuese a defender a la ciudad de Málaga, porque tenía noticias de que la armada británica-holandesa pretendía desembarcar en su puerto (35).

En 1702, arribaba en la bahía de Cádiz una armada enemiga compuesta por 50 barcos y 14.000 soldados, enviados para asaltar la ciudad (36). Málaga, viendo la cercanía del peligro, se aprestó a su defensa y a la de la zona circundante, formando el concejo una compañía, al mando del 
capitán Santaella de Melgarejo, con más de 50 caballos enfrenados y ensillados, al tiempo que acordaba:

Ejecutar en la punta del muelle una batería capaz de seis cañones. $Y$ corriendo la linea por la plaia, al levante, una media luna en donde ha de poner tres cañones. $Y$ en un sittio llamado la Peña de los Estudiantes, muy a propósito, un fuerte con quattro cañones. Y asi mismo, ha de correr la corttina desde la Puerta de los Avades hasta el muelle, que sirva de estrada encubierta. Y mirado a la parte del poniente, desde el castillo de San Andrés hasta el río, se han de hazer tres fuertes con una estrada encubierta, capaz para que la cavallería pueda correr cubierta para la defenza y envarazo de qualquiera desembarco que por esta partte intenten hazer (37).

Los costos correrían a cargo de los Propios y arbitrios de la ciudad, pero estos fondos no cubrían las cantidades necesarias para llevar a cabo lo proyectado, motivo por el cual el concejo solicita ayuda económica "a los señores Dean y cavildo de esta Santta Iglezia Cattedral y a los demás cavalleros y hombres de caudal" (38). El prelado, don Bartolomé de Espejo y Cisneros, se comprometió a conceder un préstamo de 30.000 reales, sacados "de las arcas de los depósitos y caudal de obras pías, patronatos y capellanías" - a devolver en seis meses-, con la condición de que fuesen destinados a financiar el bastión situado en el extremo del muelle (39).

En 1703, vuelve a avistarse entre Cádiz y el Estrecho otra escuadra inglesa, reanudándose las medidas de defensa en Málaga, pero será en 1704 cuando se produzcan dos hechos de relevancia: la toma de Gibraltar y la batalla naval que tuvo por escenario la bahía malacitana.

La conquista de Gibraltar puso en alerta a la capital malagueña, pues era muy factible que fuera la próxima plaza a donde se dirigieran los barcos enemigos. Como en tantas ocasiones, las autoridades locales inspeccionaron el sistema defensivo y, al igual que siempre, quedaron en evidencia una serie de carencias básicas.

La primera medida tomada por el gobernador consistió en pasar revista a las milicias concejiles, en las cuales se basaba la defensa de la ciudad y era una de las competencias militares más importantes del 
municipio, encontrándose con idénticas deficiencias a las existentes en el siglo XVII (40). En esta ocasión, la máxima autoridad municipal comprobó que la guarnición estaba compuesta por "muy poca jente, y que muchos soldados estavan sin armas, y otros que las tenían, sin pólvora ni municiones". Ante el problema de la falta de hombres, convoca un cabildo extraordinario donde se acuerda poner en pie de guerra a la generalidad de los malagueños:

Que todos los vecinos, de qualquier calidad que sean, se alisten en las companías y quarteles que a cada uno toca, para que en ofreciéndose la ocasión de tomar armas, tengan obligación de acudir con ellas a la compañía y cuartel donde estubieren alistados y acopiados para la defensa de esta ciudad (41).

Solicitando también al monarca, una vez más, que suspendiese el pago de las deudas municipales durante cuatro años, en aras de canalizar estas cantidades hacia los gastos de guerra.

$\mathrm{La}$ inminencia del ataque provocó que, mientras los soldados se atrincheraban y pertrechaban, el cabildo catedralicio mandase recoger la plata de las iglesias, hospitales y cofradías, así como los libros parroquiales, ornamentos sagrados, reliquias e imágenes para enviarlos a lugares más seguros y así salvarlos del posible saqueo. Al mismo tiempo se decidía que las monjas de clausura se refugiasen en la villa de Coín, pero poco después, el deán no creyó oportuno tal traslado, a pesar de tener preparadas las carretas para el viaje, por considerar que el posible asalto de los herejes británicos podía quedar en una simple alarma. La decisión no convenció mucho a las religiosas y, menos aún, el que los gastos de los preparativos efectuados hubiesen de correr a sus expensas (42).

En Málaga se respiraba un ambiente de lo más tenso, pues de todos era conocido que, después de tomar Gibraltar, la armada anglo-holandesa se dirigía hacia la bahía malacitana. No obstante, la esperanza también tuvo cabida en el pensamiento de la población, al conocer que una escuadra francesa había puesto rumbo a la capital, siendo avistada el 15 de agosto de 1704 a la altura de Vélez. Días después, ambas flotas se encontraron en aguas malagueñas, disponiéndose los navíos para un combate que duró nueve horas, según quedó consignado en los Libros de Cabildo de la Catedral (43). 
La dureza de la batalla fue la característica más señalada, no obstante podemos afirmar que no hubo vencedores ni vencidos, motivo por el que los dos bandos se adjudicaron la victoria. El número de bajas resultó muy elevado para ambos contendientes, ingresando en los hospitales malagueños tal cantidad de heridos franceses, que se hizo necesario habilitar los conventos y las Atarazanas para atenderlos (44).

Este fue el hecho bélico más importante que protagonizó Málaga durante la Guerra de Sucesión, pero el peligro de un nuevo ataque siguió pesando sobre sus habitantes, tomando siempre el cabildo las habituales medidas, ya comentadas, cada vez que aparecían en el horizonte las velas enemigas.

La contienda finalizaría con el tratado de Utrecht, pero persistió en España como una guerra civil, hasta que Felipe $V$ entró en Barcelona el año 1714. La transición de los Austrias a los Borbones se hacía realidad y, a partir de este momento hubo una centralización del poder, quedando reducidas las Cortes a lo que Fogel denominaría "Cámaras de registro" (45). En tanto que Calvo Poyato hace el siguiente comentario al respecto: "el desbarajuste administrativo, propiciado por una multiplicidad de inoperantes organismos burocráticos, empezaba a regularizarse a través de la nueva administración. Los informes sustituían a los memoriales" (46).

Con posterioridad, Málaga continuaría avistando barcos enemigos, pero de forma muy esporádica. No obstante, en lo referente a su defensa, cambió la improvisación típica del siglo XVII, por un sistema más operativo, cuya práctica se materializó desde los comienzos de la siguiente centuria.

Una de las cuestiones que vuelven a tomar vigencia, es la construcción de las obras del puerto malagueño, enviando Felipe $\mathrm{V}$ a ingenieros militares, generalmente de origen flamenco, para inspeccionar las obras e informar sobre el estado en que se encontraban. Entre ellos, tenemos dos destacadas figuras: Bartolomé Thurus y Jorge Próspero Verbom, quienes llegan a la ciudad en 1716 y 1722, respectivamente (47).

El primero proyectó un puerto cerrado, con la finalidad de que las arenas provenientes de los arrastres del Guadalmedina no entraran en el recinto portuario, ya que al depositarse en sus fondos imposibilitaban el ancoraje de los navios de gran calado. Por el contrario, Verbom opinaba que resultaría más eficaz construir un puerto abierto, pues con ello se evitaría el asentamiento de las arenas fluviales que, al no encontrar ningún impedimento, entrarían y saldrían fácilmente gracias a las mareas. 
La larga enfermedad sufrida por Thurus, ingeniero jefe de las obras portuarias, motivó que, en 1720, la Corona le enviase un ayudante, el ingeniero de segunda Pedro D'Aubeterre, quien introdujo algunos cambios en el plan de ejecución dispuesto por Thurus, aunque no de forma sustancial (48). Dos años más tarde, el jefe del Cuerpo de Ingenieros Militares, Jorge Próspero Verbom inspeccionaría personalmente las obras y las modificaría prácticamente en su totalidad, elaborando un informe donde rebate punto por punto el proyecto Thurus.

Hemos resumido la situación de Málaga durante los primeros y conflictivos años del Setecientos. Veamos ahora qué sucedía en Melilla durante el mismo lapsus de tiempo, donde también harán su aparición, al igual que en el siglo XVII, los ingenieros militares destinados a Málaga que, desde esta ciudad, pasaban al presidio para examinar su sistema defensivo, coincidiendo todos en el parecer de que era necesario reforzar las líneas del recinto y construir nuevos fuertes.

No ha de olvidarse que a causa del terremoto de 1660 y de los sitios sufridos por la ciudadela, se habían perdido parte de los fortificaciones exteriores, circunstancia que obligó a reforzar las murallas y agrandar los fosos, además de las obras que mencionamos anteriormente. Esta era la situación cuando sobreviene la Guerra de Sucesión que ralentiza, en parte, las reformas defensivas.

No obstante, el continuo acoso del sultán Muley Ismail Ben Xeríf, que continuamente se da durante la transición de los Austrias a los Borbones, hace que vuelva a plantearse la necesidad de ciertas rehabilitaciones o reformas, realizadas principalmente por el ingeniero Andrés de Tosso. entre las que destacan la reconstrucción de los fuertes de Santiago el Viejo y su mina de comunicación con la plaza, de San José Bajo y el de San Antonio de la Marina, del foso de los Carneros con su puente levadizo, hacer el luneto de San Felipe e instalar una batería en la glorieta de este último, sobre el torreón de la Avanzadilla; a extramuros, en el lugar donde estuvo el fuerte de Santa Ana, se levantaría el de San Miguel con su foso. Con todas estas obras empezó a conformarse el tercer recinto. Asi mismo, respecto a la "arquitectura" civil, se construyeron algunas casas en el primero.

El elemento humano también retomó sus fuerzas, no cejando de hostilizar a las fuerzas de Ismail con frecuentes salidas para destruir los llamados ataques, desde donde los musulmanes acosaban a los españoles. 
En 1701, a causa de que el sultán incrementa los asedios a Melilla, son destinados a la ciudadela 1.800 soldados, pertenecientes al Tercio de Cataluña, quienes llegan en 1702 bajo el mando del Maestre de Campo, Blas de Trinchería (49). Pero será en 1703, cuando las tropas del presidio logren un éxito resonante en uno de estos enfrentamientos, cuyo recuerdo pasará a la posteridad gracias a la relación denominada "Feliz Victoria", impresa en Barcelona, donde se asegura que entre muertos y heridos hubo "más de 2.000 moros" (50). Mas el triunfo no arredró al sultán, quién en 1715 atacó de nuevo a Melilla, interviniendo sangrientamente la famosa guardia negra, que se apoderó de los fuertes avanzados y pasaron a cuchillo a todos los que en ellos estaban, pero no conseguirían tomar la plaza y hubieron de retirarse.

Los constantes asaltos que sufría la ciudadela, provenientes del sultanato de $\mathrm{Fez}$, de las cábilas vecinas o del Mediterráneo, inciden en el hecho de que la fortaleza viva siempre a la defensiva y, para lograr un mejor sistema defensivo, se replantee la organización del espacio, dando lugar a la consolidación de un cuarto recinto, que comentaremos posteriormente (51).

Sin embargo, tal vez a causa de los reveses sufridos por Felipe $\mathrm{V}$ ante el inglés, hubo años en que el monarca dedicaba menos atención a los presidios norteafricanos y, consecuentemente a Melilla, plaza en donde repercutirían los efectos de la Guerra de la Sucesión, dado que a causa de ésta, en ocasiones, era imposible enviar el apoyo imprescindible para su subsistencia, lo cual motivó el que quedase abocada al "abandono y al hambre", hasta el extremo de que la ciudadela llegase a situaciones desesperante, sobre todo en los años 1711 y 1712 (52).

El contingente poblacional que habitaba Melilla, al igual que en centurias anteriores y salvo una minoría, era de tipo militar, pero su organización difiere un tanto respecto al siglo XVII, al estar compuesto su Estado Mayor por dos ingenieros militares, imprescindibles para la construcción de fuertes, un comisario ordenador de artillería y un tenedor del mismo cuerpo, ambos necesarios para plantear la disposición de las piezas en los distintos baluartes; pues la relación artillería-fortificaciones siempre había de estar presente. Junto a dichos mandos, existían ocho compañías de Artillería y dos formadas por gente condenada al destierro, amén de la marinería. La guarnición melillense era relevada, aproximadamente cada cuatro meses, por las tropas enviadas desde Málaga y Cádiz, pues las duras condiciones de vida en el presidio obligaba a tal medida, por cierto, muy 
mal recibida tanto por gaditanos como por malagueños, dando lugar a fuertes tensiones sociales en ambas ciudades.

Clérigos, personal sanitario y artesanos complementaban la población del recinto, junto a un escaso número de mujeres y niños (53). A este respecto, en el Reglamento sobre Presidios, del 30 de marzo de 1717 que siguió vigente hasta el 1 de enero de 1746 , quedaba regulado el que a Melilla no inmigrasen civiles, ni tampoco puediesen ir a vivir allí las mujeres solteras, ni aún las esposas de los soldados y desterrados, dado que la ciudadela estaba concebida por Felipe $\mathrm{V}$ y sus sucesores, sólo como una plaza fortificada, sin programas expansionistas, la cual debía de ser capaz de defenderse con su propia guarnición. Por tanto, en tal concepto no tenía cabida ni un movimiento poblacional de tipo civil ni la realización de actividades mercantiles:

Melilla va a ser para los Borbones, a partir de ahora, un peón destacado en la costa africana del Sultanato de Fez, por tanto un elemento de su política en la zona. $Y$ como tal sufrirá los vaivenes de esta política, desconocedora muchas veces de la función que Melilla pudiera representar.

La atención hacia ella sería pues irregular: se suceden periodos durante el siglo XVIII de verdadero esplendor, producidos por un buen abastecimiento de la ciudad, $y$ por la realización de obras tanto públicas como privadas, con otros de irregularidad y desatención donde no falta (aunque en menor proporción que en el XVII) el hambre (54).

En relación con las fortificaciones levantadas, comprobamos que desde finales del siglo XVII, la técnica de Vauban había sido aplicada paulatinamente en la construcción (55). Al avanzar la centuria del Setecientos y finalizada la Guerra de Sucesión, comenzó un periodo de auge. Así, Melilla, a partir de 1714, volverá a recibir el apoyo de la Corona. emprendiéndose una serie de reformas, como la del hornabeque de piedra y barro que se reconstruye de obra de cantera, formándose un frente abaluartado con las fortificaciones de San José Alto al sur y San Pedro al norte, situándose otro, el de San Fernando en zona avanzada, desde la cual podían defenderse las huertas, cuestión verdaderamente importante porque éstas 
producían los alimentos básicos en caso de asedio. Los edificios de servicios se multiplicaron, entre los que es de reseñar los almacenes reales de pólvora y el almacén para los víveres.

Uno de los ingenieros militares que en el siglo XVIII se traslada desde Málaga a Melilla, es Juan Martín Zermeño, jefe de las obras del puerto malacitano y capitán de ingenieros, quien en 1738 alcanzaría el grado de Ingeniero General de España (56). Zermeño había participado en el sitio de Gibraltar en 1727, y en algunos enfrentamientos de los muchos que se daban en Melilla. En 1733 llega a Melilla y, durante el gobierno de Villalba y Angulo, construyó o rehabilitó en esta plaza los fuertes de Victoria Grande, Victoria Chica, Rosario, San Fernando, San Miguel, Santa Bárbara y San Antonio. Con estas defensas se finaliza el tercer recinto y comienza a consolidarse el cuarto (57). Según Rodríguez Puget, en estos años:

Se completa el sistema de contraminas delante de San Miguel y del baluarte de San José, para proteger el glacis del flanco izquierdo de los aproches que parten de los ataques de la Vega y Quemadillo, más al norte.

En el flanco noroeste se trazan galerías de comunicación a partir del foso de San Fernando y se lleva la mina hasta las proximidades del Cubo, para contrarrestar la acción de los ataques del Cestón, entrada del Caballo, Alto y de la Puntilla.

El llano está más seguro, es menos aventurado el cultivo de los huertos bajo la protección de los fuertes de San Miguel y San José. Los fuegos cruzados de Santiago y San José con San Miguel hacen muy dificil la penetración por el flanco izquierdo.

Melilla se presta a conquistar definitivamente la
altura del Cubo: HA NACIDO EL CUARTO RECINTO (58).

Bajo la dirección de Juan Martín Zermeño se fundaría en el presidio la primera Escuela de Matemáticas, ubicada en la ermita de la Victoria, que había dejado de utilizarse para el culto. El ingeniero estaba muy enraizado en Melilla, circunstancia que se verá favorecida porque en el presidio nacerá, en 1722, su hijo Pedro Martín Zermeño y García de Paredes, 
quien siguiendo los pasos de su progenitor, proyectó varias fortificaciones en Cádiz, Cartagena y Barcelona, llegando a ocupar el cargo de Teniente General (59).

A pesar de que Felipe $V$ destinara a varios ingenieros militares a los presidios africanos con el fin de revisar, rehabilitar y construir fortificaciones, a partir de su reinado, la Corona se cuestionará el mantenimiento de los presidios norteafricanos, por considerar que el mismo resultaba muy costoso para la función militar que desempeñaban. En consecuencia, se aplicarán una serie de medidas tendentes a promover su desaparición, entre las cuales, es digna de mención la política maltusiana llevada a cabo con el fin de impedir el crecimiento demográfico en estas plazas que, basándonos en el trabajo de Morales, vamos a resumir siguiendo los principales mandatos emitidos con tal objetivo, sin olvidar que en muchas ocasiones no son nuevos, pues ya habían sido aplicados tiempos atrás, hecho que demuestra el incumplimiento de los mismos:

Así, en 1717 se prohibe la entrada de las mujeres solteras que acompañaban a los desterrados o a los soldados; en 1744, los condenados a destierro, una vez cumplida su sentencia, estaban obligados a regresar a la Península con su familia; el año 1751, sólo se deja vivir en el presidio a las guarniciones y prohiben la entrada al elemento femenino; y, en 1754, ni siquiera se admite que los desterrados vengan con sus mujeres y se manda salir a las que permanecían en la fortaleza, llegándose incluso a no permitir la estancia a criadas y nodrizas (60).

Sobre el tema habría mucho que debatir, pero excede al objeto de este trabajo. No obstante, hemos de decir que tales mandatos hicieron decaer, paulatinamente, la población melillense a lo largo de la centuria, para ascender de nuevo a mediados del siglo XIX, cuando el gobierno español decide transformar a Melilla en una factoría comercial, con la política económica de convertirla en un centro de irradiación y control hacia los territorios que la rodeaban (61). La dinámica urbana cambiará por completo y su ensanche modernista marcará la impronta de la Melilla actual (62).

En síntesis, podemos concluir que durante el tránsito de los Austrias a los Borbones, Melilla continuó manteniendo una fuerte y sólida relación con Málaga, tanto en lo referente al factor militar como al técnico, pues, si por una parte no dejaron de llegar soldados y pertrechos transportados desde el puerto malagueño, por otra, partirian desde él los ingenieros 
militares, con el mandato explícito por parte de la Corona, de mantener las defensas melillenses en las condiciones más óptimas, pero siempre supeditados a realizar sólo aquello que las habituales carencias del presidio les permitiesen. Circunstancia que, a pesar de las ostensibles diferencias geopolíticas, se daba igualmente en Málaga. En el caso de la ciudad malacitana, debido a la precaria situación económica del concejo, al que se unía el de la Real Hacienda, pues si ambas instituciones fueron muy deficitarias con Carlos II, no cambiaría su signo con el asentamiento de los Borbones en España, motivado en gran parte por el largo conflicto bélico que trajo consigo la subida al trono de Felipe V. 
1. LAARBI, A. M.: "Contribución para la comprensión del africanismo españoln, en Aldaba, $\mathrm{n}^{\circ}$ 15, UNED, Melilla, 1990, págs. 83-88.

2. Archivo Municipal de Málaga (A.M.M.), Libros de Cabildo (L. de C.), n“ 82, fol. 160. En ocasiones, los guardas y escuchas no "asistian a sus puestos", por lo cual el concejo había de tomar cartas en el asunto más veces de lo necesario. Cabildo: 11 de octubre de 1667.

3. MARTIN CORRALES, E.: "Aproximación al estudio del corsarismo en el litoral norteafricano en el siglo XVIII", en Aldaba, $n^{\circ}$ 9, Monográfico sobre Melilla, UNED, Melilla, 1987, págs. 25-39

4. A.M.M., L. de C., $n^{\circ} 89$, fol. 36. Cabildo: 16 de marzo de 1673.

5. Ibidem. Abundantes datos sobre el tema están registrados en la Escribanía de Cabildo.

6. PEREZ DE COLOSIA RODRIGUEZ, $\mathbf{M}^{\circ}$ I.: "Envío de soldados desde Málaga a Ceuta y otros presidios norteafricanos (siglo XVII) Ponencia presentada en el /I Congreso Internacional El Estrecho de Gibraltar, Ceuta, 1990 (en prensa).

7. A.M.M., L. de C., n" 103, fols. 376-379. Cabildo: 30 de julio de 1693.

8. Ibídem, fols. 69-74v. Cabildo: 25 de abril de 1692 .

9. OLMEDO CHECA, M.: "Gestión, auge y decadencia de las obras del puerto malagueñon, en El Puerto de Málaga. 30 siglos de vida, 400 años de historia, Junta del Puerto, Málaga, 1988, págs. 115-117.

10. Servicio Histórico Militar (S.H.M.), Colección José Aparici, fols. 310-312. Es una copia de la memoria elaborada por Toreli, enviada del Archivo General de Simancas, inserta en la recopilación documental realizada por Aparici, donde se incluye también el plano levantado por dicho ingeniero. En ella pone año de 1694, pero el 4 está puesto sobre un 3, que debe ser el número correcto. (Archivo General de Simancas, Guerra Antigua, Leg. 2.972).

11. PEREZ DE COLOSIA RODRIGUEZ, $M^{\circ}$ l. y GIL SANJUAN, J.: "Málaga en tiempos de Felipe IV", en Baetica, ${ }^{\circ} 4$, Facultad de Filosofia, Málaga, 1981, págs. 209-226.

12. A.M.M., L. de C., $\mathrm{n}^{\circ} 98$, fols. $368-370$. Cabildo: 5 de septiembre de 1684 .

13. PEREZ DE COLOSIA RODRIGUEZ, $M^{a}$ I.: "Las puertas de la ciudad de Málaga (siglos XVI-XVIII)" en Homenaje a Francisco Bejara- no, Real Academia de Bellas Artes de San Telmo, Málaga, 1991, págs. 57-82.

14. S.H.M., supra.

15. A.M.M., Colección de Originales (C. de 0.), $n^{\circ} 31$, fols. 409-411v. Real cédula emitida en Madrid el 12 de diciembre de 1695; L. de C., $\mathrm{n}^{\circ}$ 103, fols. 400-401 y 417-417v. Cabildo: 22 de septiembre de $1693, \mathrm{y} \mathrm{n}^{\circ} 105$, fols. 92-95v. Cabildo: 5 de abril de 1696.

16. CABRERA PABLOS, F. R.: "Defensas militares malagueñas en el primer tercio del siglo XVIII", Comunicación presentada en el Congreso Ciudad y Mar en la Edad Moderna, Cartagena, 1984 (en prensa).

17. A.M.M., C. de 0 ., $n^{\circ} 31$, fols. $411 v-414$. Real despacho dado en Madrid el 2 de junio de 1702.

18. BRAVO NIETO, A.: “La ocupación de Melilla en 1497 y las relaciones entre los Reyes Católicos y el duque de Medina Sidonia", en Alda$b a, \mathrm{n}^{\circ} 15$, UNED, Melilla, 1990, págs. 15-37.

19. MEDINA, P. de: "Crónica de los muy excelentes Duques de Medina Sidonia...", Colección de Documentos Inéditos para la Historia de Espana, Tomo XXXIX, Madrid. Cfr. IBARRA RODRIGUEZ, E.: La Conquista de Melilla en 1497 y BRAVO NIETO, A. y SAEZ CAZORLA, J. M.: Melilla en el siglo XVI a través de sus fortificaciones, Ayuntamiento de Melilla, 1988 y "Melilla en el siglo XVI, un ensayo sobre fortificación", en Castillos de España, n 94, Asociación Española de Amigos de los Castillos, Madrid, 1987, págs. 3-18.

20. La naturaleza del casco histórico de Melilla, así como la evolución de sus fortificaciones, han sido objeto de un prolijo estudio realizado por el equipo formado por A. BRAVO NIETO y J. M. SAEZ CAZORLA, coordinado por S. MORENO PERALTA, cuyos resultados se han publicado en un libro titulado: Historia de las fortificaciones de Melilla (Memoria histórica), en "Plan especial de rehabilitación de los cuatro recintos fortificados", Ayuntamiento de Melilla, 1989, resumido también en el artículo "Plan especial de rehabilitación de los cuatro recintos fortificados de Melilla", en Geometría, n 7 , Málaga, 1989, págs. 9-23.

21. Ibidem, Historia de las fortificaciones..., págs. 18-20. En el apartado dedicado a la valoración de las construcciones civiles, se sintetiza las características más destacadas de las viviendas. Cfr. BRAVO NIETO, A.: "Un edificio singular en Melilla la Vieja: la Casa de los Lafont", en Cua- 
dernos de Historia de Melilla, $\mathrm{nl}^{\prime \prime} 1$, Asociación de Estudios Melillenses, Melilla, 1988, págs. 35-40.

22. A partir del siglo XVI, en Melilla se levantarán una serie de fortificaciones que irán ampliándose durante toda la Edad Moderna, según podemos comprobar en la relación aportada por SALZ CAZORLA, J. M. y BRAVO NIE'TO, A.: "Aproximación a la cartografía de Melilla (hasta 1862)", en Truipana, n 1 , Asociación de Estudios Melillenses, Melilla, 1987, págs. 40-46.

23. "Algunas visiones solre la Melilla del siglo XVI", en Colección Historia de Melilla en sus tex1os, $\mathrm{n}^{\circ} 2$, Asociación de Estudios Melillenses, MeliIla, 1990, págs. 17-20. Se trata de una selección de textos traducidos por E. GOMEZ RAMOS, de la obra CASITRIES, H. de, RICARD, R. y VERONNE, Ch., de la: Les Sources Inédites de l'histoire du Moroc. En cl texto se enumera la gente de guerra, así como los civiles, eclesiásticos y esclavos.

24. Si respecto al personal civil Melilla dependía mucho de Málaga, con más motivo el eclesiástico, dado que la Iglesia melillense estaba bajo la jurisdicción del obispado malacitano. Cfr. BRAVO NIETO, A.: "La iglesia de la Purísima Concepción en Melilla la Vieja", en Trúpana, n" 1, Asociación y "La Virgen de la Victoria en Melilla", en Lloy en Melilla, 6 de septiembre de 1986, págs. 6-7.

25. SALAFRANCA ORTEGA, J.: Bosquejo histórico de la población y guarnición de Melilla (1497-1874), Ayuntamiento de Melilla, 1987; "Síntesis histórica de la población judiáa de Melilla (1497-1936)" en Aldaba, $n^{\circ}$ 9, Monográfico sobre Melilla, UNED, Melilla, 1987, págs. 55-65 y La presencia hebrea en Melilla hasta 1874, UNED, Melilla, s.a.

26. MORENO PERALTA, S., BRAVO NIETO, A., y SAEZ CAZORLA, J. M.: Historia de las fortificaciones..., págs. 44-45. Los datos están tomados de CABALLLERO, F. y otros: Relación $y$ descripción del Presidio y Plaza de Melilla, 1794 (Servicio Histórico Militar, 4-5-7-10, n 6.395, fol. 26).

27. Ibidem, págs. 49-53.

28. KAMEN, H.: La España de Carlos II, Crítica, Burcelona, 1981, pág. 89.

29. ARGENTE DEL CASTILLO SANCHEZ, F. J.: Melilla: génesis y desarrollo de una ciudad sobre un territorio de soberanía. Del presidio al espacio urbano, Tesis Doctoral Inédita, Málaga, 1990, pág. 47.

30. MORENO PERAL'TA, S., BRAVO

NIETO, A. y SAEZ CAZORLA, J. M.: Historia de las fortificaciones..., págs. 62-69.

31. KAMEN, H.: La Guerra de Sucesión en España. 1700-1715, Grijalbo, Barcelona, 1974.

32. A.M.M., L. de C., n $^{\circ} 116$, fols. 733-735. Cabildo: 23 de noviembre de 1716.

33. CABRERA PABLOS, F. R.: "La impronta de los Borbones", en El puerto de Málaga. 30 siglos de vida, 400 años de historia, Junta del Puerto, Málaga, 1988, pág. 123.

34. Ibídem, El puerto de Málaga a comienzos del siglo XVIII, Universidad de Málaga, 1986.

35. DIAZ DE ESCOVAR, N.: Décadas malagueñas, 1700-1709, cjemplar mecanografiado.

36. DOMINGUEZ OR'TIZ, A.: "Andalucía en el siglo XVIII" en Historia de Andalucia, Planeta, T. IV, Barcelona, 1981, pág. 51 y, CALVO POYATO, J.: Guerra de Sucesión en Antalucía, Diputación Provincial, Córdoba, 1982, pág. 22.

37. A.M.M., L. de C., $n^{\circ} 109$, fols. 126-126v. Cabildo: 7 de junio de 1702 .

38. Ibidem, fols. $126 \mathrm{v}-127$.

39. Ibidem, fol. 171v. Cabildo: 5 de septiembre de 1702.

40. PEREZ DE COLOSIA RODRICUEZ, $\mathrm{M}^{\mathrm{n}}$ I.: "Competencias militares del cabildo malagueño a finales del siglo XVII", Ponencia presentada en las $X$ Jornadas de Andalucia y América, Universidad Hispanoamericana Santa María de la Rábida, Huelva, 1991 (en prensa).

41. A.M.M., L. de C., $n^{\circ} 110,105 v-106$ v. Cabildo: 30 de junio de 1704 .

42. Archivo de la Catedral de Málaga (A.C.M.), n" 38, fols. 291v-293v. Cabildo: 11 de agosto de 1704 .

43. Ibidem, fols. 294-294v.

44. CABRERA PABLOS, F. R.: "La batalla naval de 1704 en aguas de Málaga”, en Jábega, $n^{\circ} 36$, Diputación Provincial, Málagn, 1981, págs. $34-43$.

45. FOGEL, M.: "Apogeo o decadencia de los absolutismos tradicionales: Francia y España", en Historia Universal, T. VI, Salva1, Barcelona, 1982, págs. 289-290.

46. CALVO POYATO, J.: op. cit., págs. 13-14.

47. PEREZ DE GOLOSIA RODRIGUEZ, M I.: "Proyecto de Bartolomé Thurus para el puerto de Málaga”, en Baetica, $n^{\circ}$ 6, Facultad de Filosofía y Letrus, Málaga, 1983, págs. 275-282 y "Los ingenieros militares y el puerto de Málaga: el informe de Jorge Próspero Verbom", Comunicación presentada al Congreso histórico Ciudad $y$ 
mar en la Edad Moderna, Universidad de Murcia, 1984 (en prensa).

48. CABRERA PABLOS, F. R.: El Puerto de Málaga a comienzos..., págs. 46-141.

49. MORENO PERALTA, S., BRAVO NIETO, A. y SAEZ CAZORLA, J. M.: Historia de las fortificaciones..., pág. 70.

50. Relación de la Feliz Victoria que han conseguido las armas del Rey Nuestro Señor en la Plaza de Melilla, contra los Moros, el día 24 de mayo de este presente Año de 1703, Im. Francisco Guasch, Barcelona, 1703. Inserto en el libro de MIR BERLANGA. F.: Melilla la desconocida. Itisloria de una ciudad española, editada por el propio autor en Melilla, 1990, págs. 78-82.

51. BRAVO NIETO, A. y SAEZ CAZORLA, J. M.: "Fortificaciones en el siglo XVIII, el Cuar1o Recinto de Melilla la Vieja", en Trúpana, $n^{\circ} 2$. Asociación de Estudios Melillenses, Melilla, 1988. págs. 29-42.

52. MORENO PERALTA, S., BRAVO NIETO, A. y SAEZ CAZORLA, J. M.: Historia de las fortificaciones..., pág. 71.

53. ARGENTE DEL CASTILLO SANCHEZ, F. J.: op. cit., pág. 48.

54. MORENO PERALTA, S., BRAVO NIETO, A. y SAEZ CAZORLA, J. M.: Historia de las fortificaciones..., pág. $7 \overline{5}$.

55. RODRIGLEZ PUGET, J.: "Cionsideraciones acerca de la defensa de la plaza de Melilla y su campo exterior a finales del siglo XVII, que. sirven de base para el análisis de la evolución del cuarto recinto defensivo de Melilla. Siglo XVIII", en Actas del Congreso Melilla en la Historia de sus fortificaciones, Ministerio de Cultura, Melilla, 1991, púgs. 59-63.

56. CABRERA PABLOS, F. R.: El puerto de Málaga a comienzos..., págs. 154-172.

57. BRAVO NIETO, A. Y SAEZ CAZORLA, J. M.: Fortificaciones en el siglo XVIII: el Cuarto Recinto..., págs. 29-42.

58. RODRIGUEZ PUGET, J.: Consideraciones acerca de la defensa..., pág. 63.

59. CAPEL, H. y otros: Ingenieros militares en lispaña. Siglo $X H^{\prime} I I I$, Universidad de Barcelona; 1983, págs. 309-313 y 314-317. Cfr. MIR BERLANGA, F.: op. cit., pág. 83.

60. MORALES Y MENDICUTIA, G. de: "Datos para la historia de Melilla", Telegrama del Rif, Melilla, 1908, págs. 71-81.

61. MLÑOZ DOMINGUEZ, J.: La fiscalidad de los territorios de Ceuta y Melilla, UNED, Melilla. s.a.

62. RODRIGUEZ PLGET, J.: "Bases urbanísticas para el desarrollo de Melilla Modernista", en Actas del Simposio Nacional El barco como metáfora visual y vehiculo de transmisión de formas, Consejería de Cultura de la Junta de Andalucía-Universidad de Málaga, 1985, págs. 291-308. 


\section{Melilla.-Llegada del correo.}






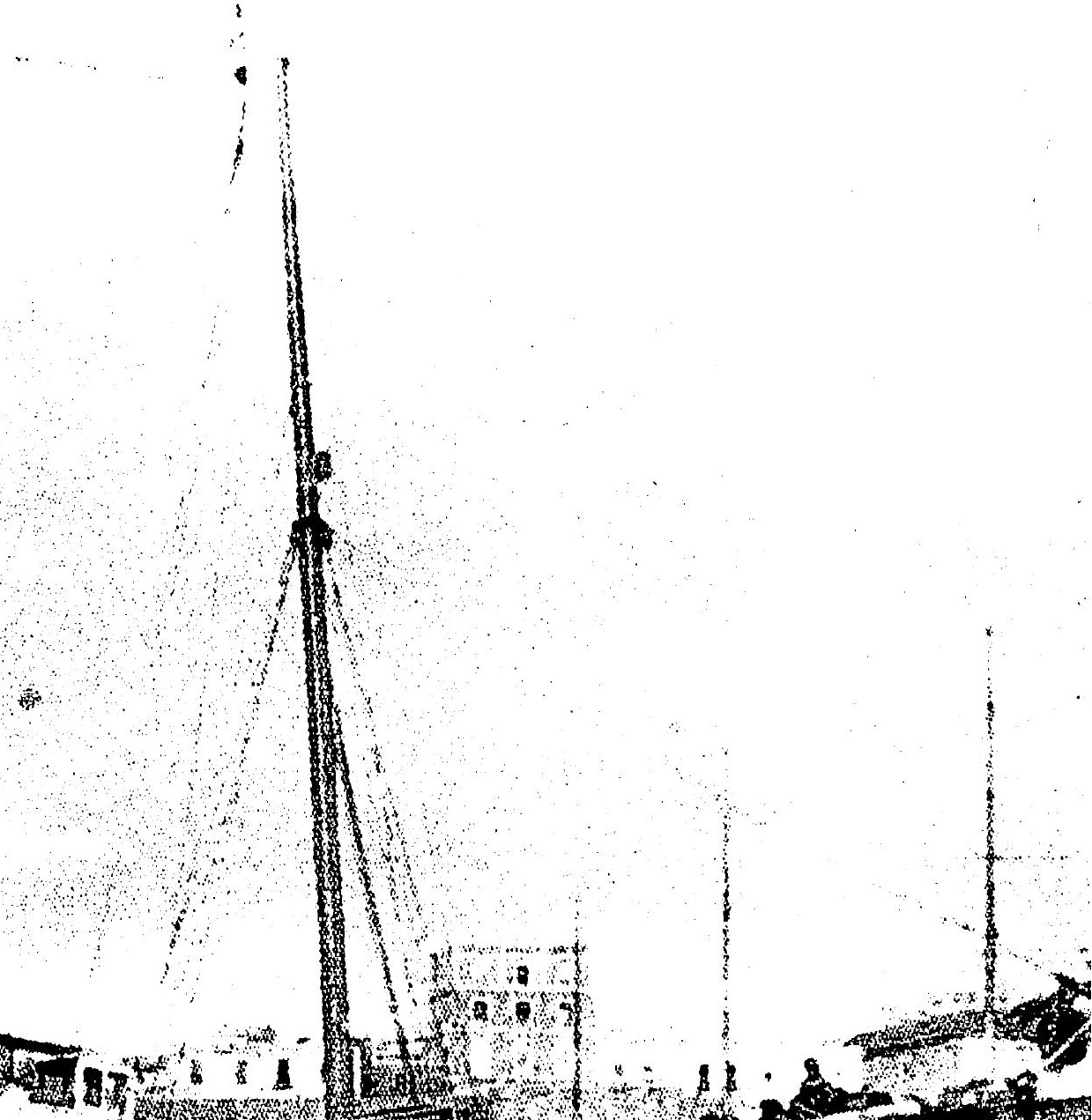

䄼 1.2.

tit

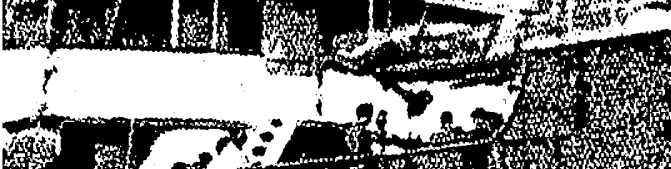

ansint

$$
\text { : }
$$

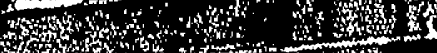

S

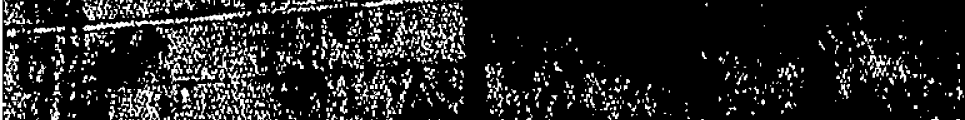

Hox

Why

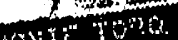

\section{(n)}

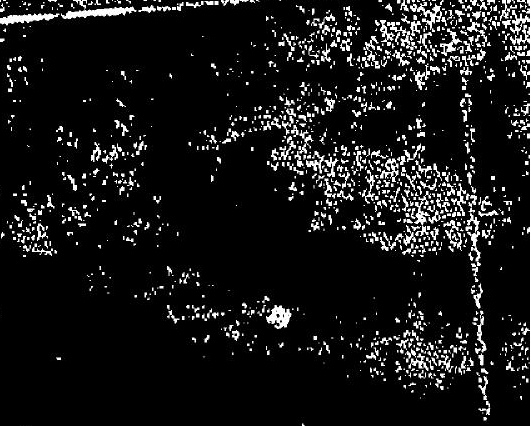

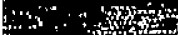

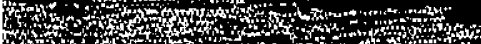

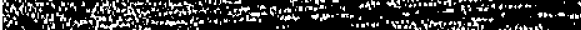

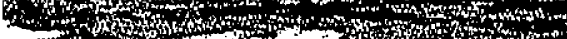

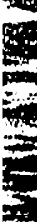

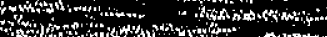

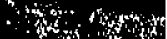

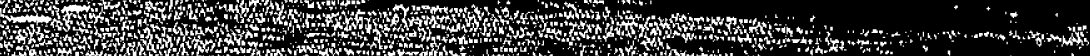

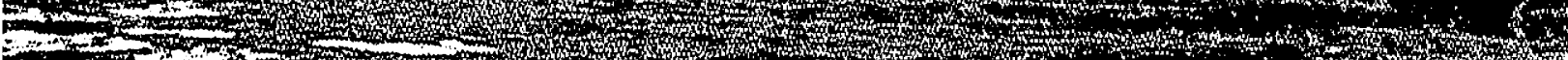

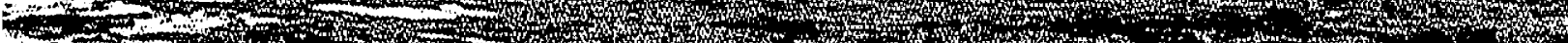

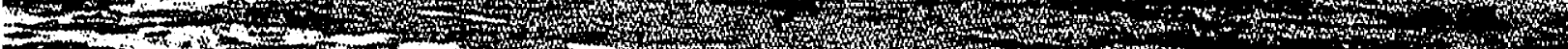
7 -

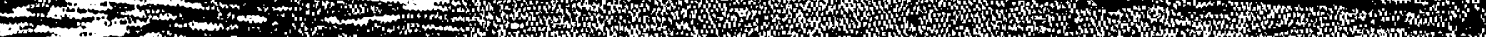

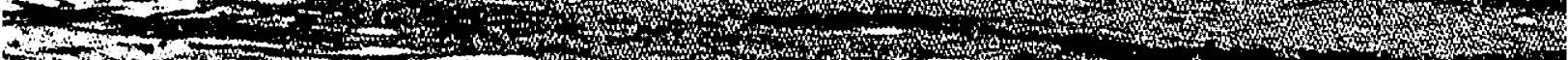
7 tom

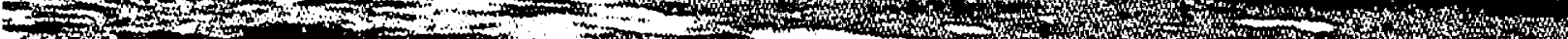
3. ${ }^{2}$ 